University of Nebraska - Lincoln

DigitalCommons@University of Nebraska - Lincoln

$9-2006$

\title{
Understanding the Influence of Climate Forecasts on Farmer Decisions as Planned Behavior
}

Ikrom Artikov

Stacey Hoffman

Gary Lynne

Lisa M. PytlikZillig

Q. Steven $\mathrm{Hu}$

See next page for additional authors

Follow this and additional works at: https://digitalcommons.unl.edu/lpz

Part of the Administrative Law Commons, Counseling Commons, Dispute Resolution and Arbitration Commons, Family Law Commons, Juvenile Law Commons, Law and Psychology Commons, Law and Society Commons, Psychology Commons, and the Public Law and Legal Theory Commons

This Article is brought to you for free and open access by the Public Policy Center, University of Nebraska at DigitalCommons@University of Nebraska - Lincoln. It has been accepted for inclusion in Lisa PytlikZillig Publications by an authorized administrator of DigitalCommons@University of Nebraska - Lincoln. 
Authors

Ikrom Artikov, Stacey Hoffman, Gary Lynne, Lisa M. PytlikZillig, Q. Steven Hu, Alan Tomkins, Kenneth Hubbard, Michael Hayes, and William J. Waltman 


\title{
Understanding the Influence of Climate Forecasts on Farmer Decisions as Planned Behavior*
}

\author{
Ikrom Artikov, ${ }^{+}, \#$ Stacey J. Hoffman, ${ }^{\#}$ Gary D. Lynne, ${ }^{+}, @$ Lisa M. Pytlik Zillig, $\&$ Qi Hu, ,** $^{* *}$ \\ Alan J. Tomkins, ${ }^{\#}$ Kenneth G. Hubbard, ${ }^{@}$ Michael J. Hayes, ${ }^{@}$ and William Waltman ${ }^{+}+$ \\ + Department of Agricultural Economics, University of Nebraska at Lincoln, Lincoln, Nebraska \\ \# Department of Psychology, and Nebraska Public Policy Center, University of Nebraska at Lincoln, Lincoln, Nebraska \\ @ School of Natural Resources, University of Nebraska at Lincoln, Lincoln, Nebraska \\ \& Center for Instructional Innovation, University of Nebraska at Lincoln, Lincoln, Nebraska \\ ** Department of Geosciences, University of Nebraska at Lincoln, Lincoln, Nebraska \\ ++ Department of Agronomy, University of Nebraska at Lincoln, Lincoln, Nebraska
}

(Manuscript received 6 June 2005, in final form 20 April 2006)

\begin{abstract}
Results of a set of four regression models applied to recent survey data of farmers in eastern Nebraska suggest the causes that drive farmer intentions of using weather and climate information and forecasts in farming decisions. The model results quantify the relative importance of attitude, social norm, perceived behavioral control, and financial capability in explaining the influence of climate-conditions information and short-term and long-term forecasts on agronomic, crop insurance, and crop marketing decisions. Attitude, serving as a proxy for the utility gained from the use of such information, had the most profound positive influence on the outcome of all the decisions, followed by norms. The norms in the community, as a proxy for the utility gained from allowing oneself to be influenced by others, played a larger role in agronomic decisions than in insurance or marketing decisions. In addition, the interaction of controllability (accuracy, availability, reliability, timeliness of weather and climate information), self-efficacy (farmer ability and understanding), and general preference for control was shown to be a substantive cause. Yet control variables also have an economic side: The farm-sales variable as a measure of financial ability and motivation intensified and clarified the role of control while also enhancing the statistical robustness of the attitude and norms variables in better clarifying how they drive the influence. Overall, the integrated model of planned behavior from social psychology and derived demand from economics, that is, the "planned demand model," is more powerful than models based on either of these approaches alone. Taken together, these results suggest that the "human dimension" needs to be better recognized so as to improve effective use of climate and weather forecasts and information for farming decision making.
\end{abstract}

\section{Introduction}

Decision making involves applying principles and mechanisms weighing a range of factors in multiple dimensions surrounding a particular question or concern. For example, many factors contribute to the decision of planting a certain crop or buying a certain amount of

\footnotetext{
* Agricultural Research Division, University of Nebraska at Lincoln, Contribution Number 14825.

\#\# Current affiliation: Global Market Research, Pioneer HiBred International, Johnston, Iowa.

Corresponding author address: Dr. Gary D. Lynne, 103B Filley Hall, University of Nebraska at Lincoln, Lincoln, NE 68583-0922. E-mail: glynne1@unl.edu
}

federal crop insurance. Because climate is only one of the factors that decision makers may use to inform their decisions, the relationship of climate prediction to other factors and the role of climate information in the context of individuals' existing knowledge, beliefs, and values can help to explain decisions and other behavioral outcomes. As Hulme et al. (1992, p. 116) point out, "a forecast in isolation from other information is unlikely to improve on existing indigenous knowledge systems" and, thus, is unlikely to be the only basis for making decisions. Upon what, then, are decision makers basing their decisions? Though approaches taken by economists such as Sonka (e.g., Sonka et al. 2001) emphasize information relevant to personal profit maximization, others have argued that the decision-making context also consists of many "rules of thumb" based on 
past experience and is influenced by personal beliefs, community values and commitments, and economic capacity, among other factors that guide an individual's decision making (e.g., Nicholls 1999).

How are these multiple influences weighed and used in a rational decision with climate forecasts and other forms of climate information? These questions can be addressed using tools and perspectives from the social sciences, and a number of social science theories and methods have already been applied to understand decisions and perceptions in the context of climate forecasts and natural resources (e.g., Wright and Ayton 1987; Taylor et al. 1988; Stewart et al. 1989, 2004; Stewart and Lusk 1994; Lynne et al. 1995; Nicholls 1999; Willock et al. 1999; Beedell and Rehman 1999, 2000; Cutforth et al. 2001; Trumbo and O'Keefe 2001). Several of these theories come from the fields of behavioral economics, judgment and decision making, and theories of attitudes, including how attitudes influence behavior [for helpful overviews, see Kahneman et al. (1982), Hammond et al. (1986), Plous (1993), Ajzen (1996), Connolly et al. (2000), Dawes and Hastie (2001), Hastie (2001), Gilovich et al. (2002), and Kahneman (2003)]. Such social scientific inquiries will augment the steps taken by meteorologists and climatologists to improve the use of forecasts. Knowledge from the disciplines of behavioral economics, judgment and decision making, and social psychology-in combination with research activities in agronomy, agricultural economics, cultural and physical geography, and the sciences of meteorology, climatology, and oceanography-can help to create new understanding of important decision behaviors and activities relating to use of climate forecasts. Furthermore, information discovered through such multidisciplinary and interdisciplinary investigations may guide new scientific knowledge at the interstices of these disciplines.

In a companion paper, $\mathrm{Hu}$ et al. (2006) clarify that the purpose of this research is to find a more solid, scientific basis for understanding and then improving farmer use of weather and climate information and forecasts in farming decisions. This capability becomes ever more important as farmers and others seek ways to adapt decisions to changing climatic conditions. $\mathrm{Hu}$ et al. (2006) focus on general statistical tendencies in the survey data, including analysis of ranges, means, and correlations. This paper goes beyond $\mathrm{Hu}$ et al. (2006) by shifting the focus to what actually motivates the use of weather and climate information and forecasts and, more important, what drives the influence of said information and forecasts on farmer decisions.

In particular, this article develops the capability 1) to predict the probability that weather and climate infor- mation and forecasts of various kinds will influence farmer decisions and 2), for those being influenced, to predict the degree of the influence. These predictions are related empirically to an integrated combination of variables suggested by theoretical considerations in social psychology and behavioral economics.

\section{Theoretical and empirical models}

Recall the theory of planned behavior (TPB; Ajzen 1985, 1991) in the companion paper by $\mathrm{Hu}$ et al. (2006):

$A \approx I=f$ (attitude, social norms, perceived control),

where $A$ is action, $I$ is intention, and $f$ is a function of the causal factors on intention and action. Integrating Eq. (1) with the main ideas from the theory of derived demand gives the TPB even greater explanatory power (Lynne and Rola 1988); as noted in Hu et al. (2006), the enhanced version of the theory is referred to as the theory of planned demand (TPD). The TPD integrates the effects of financial capability (after Lynne and Rola 1988) and geographical environment in Eq. (1) and has the general form

$$
\begin{aligned}
A \approx I= & f(\text { attitude, social norms, perceived control, } \\
& \text { financial capability, environment). }
\end{aligned}
$$

The TPB and TPD provide a useful framework for understanding farmer motivation and intentions to use or not to use the forecasts.

In this paper, we focus attention on the actual behavior $A$, defined as the extent to which weather information and forecasts are having an influence, as perceived by farmer decision makers. Moving toward giving empirical meaning to the model in Eq. (2) and defining the extent and degree of influence in probability terms, we have

$$
\begin{aligned}
\operatorname{Prob}(0, X)= & \beta_{1} \sum_{j=1}^{J} b_{j} e_{j}+\beta_{2} \sum_{k=1}^{K} n_{k} m_{k}+\beta_{3} \sum_{l=1}^{L} c_{l} p_{l} \\
& +\beta_{4} R+\beta_{5} L+\beta_{0}
\end{aligned}
$$

where $\beta_{0}$ is a constant. The dependent variable on the left-hand side of Eq. (3) describes the probability of being influenced (represented by $X$ ) rather than not being influenced (represented by 0 ) and, for those being influenced $(X>0)$, the magnitude of the influence.

The first three independent variables on the righthand side (rhs) of Eq. (3) are suggested by the widely applied TPB. Ajzen (1985) first proposed the TPB, suggesting that intentions and actions can be explained by three variables: attitudes, social norms, and perceived behavioral control, each consisting of an expectancy 
multiplied by an evaluation. For example, an "attitude" is measured by a product of the belief or expectancy that an action will lead to an outcome $\left(b_{j}\right)$ and the value of the outcome $\left(e_{j}\right)$. Farmers who believe that the use of climate information has a high probability of helping them to increase their profits and who value increased profits should be more likely to use that climate information. Meanwhile, others who have less confidence in the utility of climate information or who value increased profits less should be less inclined to use forecasts, when other important factors are held constant.

The "social norm" component is a product of belief $\left(n_{k}\right)$ that others view an action as appropriate and the value of complying with those views $\left(m_{k}\right)$. Social norms in this model can also be thought of as a person's perception of the social pressure to perform the behavior. For example, if farmers think it is probable that many people want them to use climate information, and if they believe strongly that they should comply with others' wishes, then the felt social pressure to use climate information would be high.

Last, "perceived behavioral control" [PBC, the third term on the rhs in Eq. (3)] represents perceptions about the ease with which the action can be taken by the individual, including the idea of constraints imposed by others. Such control reflects an individual's various beliefs about personal access to or control over various resources and factors $\left(c_{l}\right)$ and extent to which various factors will constrain or facilitate his/her ability to perform the action $\left(p_{l}\right)$.

Ajzen $(2002$, p. 2) indicates that "vexing problems remain" with respect to this control variable, which we further address in the empirical analysis herein. Ajzen notes specifically the "conceptual and methodological ambiguities surrounding the concept of perceived behavioral control," because it includes both "perceived self-efficacy," which is a construct that deals largely with an individual's belief that he/she possesses skills and abilities necessary to perform a behavior (Bandura 1997 cited in Ajzen 2002, p. 3), and "perceived controllability," which refers to the extent to which one believes it is possible to control a situation at all regardless of one's skills and abilities. The control phenomenon is a highly debated topic in the literature, and a large number of articles explore the phenomena of controllability and self-efficacy. Terry and O'Leary (1995) suggest that these variables are empirically different and have distinct effects (see also Manstead and van Eekelen 1998). Armitage and Conner (1999) tested the predictive validity of control components and supported Terry and O'Leary's findings. Sparks et al. (1997) also modified perceived control and suggested measuring it with "perceived difficulty" that would cap- ture both self-efficacy and controllability. That is, these two measures are generally viewed as somehow independent but additive.

In our view, these two facets of PBC are interdependent. If a farmer has not only worked hard to enhance his abilities in using the forecasts (i.e., self-efficacy) but is also paying more attention to their accuracy, timeliness, and other characteristics (i.e., controllability), we would expect the forecast influence to be greater on $\mathrm{him} / \mathrm{her}$. This expectation is modeled by multiplying the two measures together, such that a small value of the index is associated with both low self-efficacy and low controllability, and a large value with both measures being high. Combinations of low self-efficacy/high controllability or high self-efficacy/low controllability will give midrange value of this index. We would expect that the smaller this index is the less likely it is that forecasts will influence decisions.

Another aspect of control, preference for control, is not well represented in Ajzen's PBC construct. It relates to the extent to which farmers want control over their farms. Some farmers, depending on their personality, may want more control while others may be more likely to "go with the flow." The desire for more control would likely complement one's perception of selfefficacy and controllability. Thus, a complete PBC construct will constitute the three control factors (controllability, self efficacy, and preference for control) multiplied together. This would increase the probability of decisions being influenced by weather and climate forecasts and information and, for those who are influenced, increase the degree to which they are influenced.

In this study, we also added an "actual control" variable represented in financial capability $[R$, the fourth term on the rhs of Eq. (3)]. As Lynne et al. (1995, p. 585) claim, "economic reasoning suggests the need to add actual financial control," a contention that is statistically supported in that paper. Including a financial variable also recognizes the motivation for more profits; applying weather information and forecasts needs to be at least somewhat profitable as well as to serve other motivations held by farmers. Farm sales serve as this variable in the regression modeling, with an expected positive affect on the probability of weather and climate influence.

A location variable $L$ that indicates the farmers' geographic location and environment is also included in Eq. (3), because of the likely effects of spatial climate variability and resource availability. The latitude and longitude coordinates of farms were used to determine their locations. The expectation was that farmers located farther to the west in Nebraska, being closer to the more arid Great Plains area, would be more heavily 
dependent on weather and climate as the resources become scarce (e.g., forecasts of growing-season rainfall are more important to decisions in this location than are similar forecasts in wet regions). Those living farther north would perhaps have a similar dependence on weather and climate as those in the west, because climate variability increases as one moves north.

By including the financial and location influences on decision behavior, the TPD [Eq. (3)] extends the social psychology-based TPB approach to decision processes related to forecast use and provides a powerful tool for gaining understanding of those processes.

\section{Data collection, variable measurement, and component selection}

\section{a. Data collection}

Data suggested within the context of the TPB and TPD for understanding social and economic influences on farming decisions related to use or nonuse of climate information were collected with the survey described in $\mathrm{Hu}$ et al. (2006). Farmers from three counties in southeastern Nebraska were surveyed. The survey instrument was designed in autumn of 2002 using focus-group techniques and was administered in Fillmore, Otoe, and Seward Counties in Nebraska. Overall, 724 farmers, or $33 \%$ of those surveyed, responded. Of the 724 responding surveys, 26 were incomplete and were excluded. Analysis of the 698 valid surveys showed that the demographic characteristics and agricultural profile of the samples are within the $90 \%$ confidence interval in each county. In addition, correlations between survey items confirmed internal consistency of the survey questions and their answers ( $\mathrm{Hu}$ et al. 2006), suggesting that the respondents understood those questions correctly.

\section{b. Dependent-variable measurement and component selection}

As noted in $\mathrm{Hu}$ et al. (2006), we developed measures of farmer behavior for the dependent variables from answers to the survey inquiry: "Please rate the extent to which weather forecasts and information influenced each decision in 2002." The scale starts with " $0=$ No, it did not influence my decision" and, then, ranges from "1 (A little)" to "6 (A great deal)" under the umbrella of "Yes, it did influence my decision." The listed five groups of farming decision behaviors, each measuring a different facet of behavior during a growing season, are agronomic decisions (determining crop type, seed variety, tillage, planting density, and date), purchasing crop insurance, summer growing-season decisions (determining amount and time of using pesticides, herbicides, fertilizer, and irrigation), harvest and postharvest deci- sions like autumn tillage, and crop marketing. The weather and climate information considered in the survey are grouped into three types: current and recentpast conditions (CRPC), short-term forecasts (STF), and long-term forecasts (LTF). The result is a $5 \times 3$ matrix, that is, 15 different possible dependent variables, each reflecting a potentially different degree of influence. It was decided that it was not practical to work with so many different dependent variables (although the dataset is available for doing so such that further analysis can continue, looking at "each cell" in the matrix), and so some means was sought to delineate a smaller subset of component parts.

This was accomplished using principal component (PC) analysis (e.g., Kim and Mueller 1978). This analysis finds the overlaps in the influences on farming decisions and, because the influences are associated with forecasts of different time scales in the survey, helps to point to the distinguishing differences in the role of such time-related forecasts. Results of the PC analysis, specifically from the Varimax with Kaiser normalization (Kim and Mueller 1978), show significant loading in three distinctive areas of influence, suggesting three behavioral influence (dependent) variables (see the appendix): 1) influence on agronomic decisions, which include agronomic decisions through planting, summer growing-season decisions, and harvest/postharvest decisions, 2) influence on crop insurance decisions, and 3) influence on marketing decisions. It was also found that for the agronomic decisions the influence of the STF could be combined with the CRPC, whereas LTF needed to be kept separate, thus showing the need to consider two agronomic dependent variables to reflect the different time scales. The net result is four probability models (four unique dependent variables) composed of two agronomic models, each reflecting a different time dimension: one crop insurance model and one crop marketing model.

\section{c. Independent-variable measurement}

As described in some detail in $\mathrm{Hu}$ et al. (2006), the first three independent variables on the rhs of Eq. (3) are expectancy-value measures in the standard "belief (expectancy) $\times$ value (utility)" format. So, all three terms are also proxies for the subjective utility of the behavior, as defined in economics (Vodopivec 1992), and measure what farmers perceive they are gaining from using weather information and forecasts as the overall payoff is produced by the subjective utility gained in each of these three dimensions.

Terms to measure each of the first three independent variables on the rhs of Eq. (3) were constructed following the general recommendations in Ajzen (1988) and 
TABLE 1. Bagozzi test results showing components of the overall view suggesting that forecasts influence decisions. The overall view, the general attitude toward weather information and forecasts serving as the global view variable in the Bagozzi test, is measured by the question, "In your experience, letting weather forecasts and information influence your crop-related decisions has been," with responses measured on two scales: "extremely useless" to "extremely useful" and "extremely bad" to "extremely good." The responses were added to form the global view variable (superscript "a" denotes significance level $p<0.10$, superscript "b" denotes $p<0.05$, and superscript "c" denotes $p<0.01$ ). Here, $a_{3}$ is defined in Eq. (4) and $R^{2}$ denotes the proportion of the variance explained.

\begin{tabular}{|c|c|c|c|c|c|c|}
\hline \multirow[b]{2}{*}{ Components } & \multicolumn{2}{|c|}{ Current and recent-past conditions } & \multicolumn{2}{|c|}{ Short-term forecast } & \multicolumn{2}{|c|}{ Long-term forecast } \\
\hline & $a_{3}$ & $R^{2}$ & $a_{3}$ & $R^{2}$ & $a_{3}$ & $R^{2}$ \\
\hline $\begin{array}{l}\text { Planting the best crop and variety; optimum } \\
\text { spring tillage; best planting density and } \\
\text { planting date }\end{array}$ & $0.048^{\mathrm{c}}$ & 0.17 & $0.053^{\mathrm{c}}$ & 0.18 & $0.052^{\mathrm{c}}$ & 0.23 \\
\hline Right amount of crop insurance & $0.049^{c}$ & 0.08 & $0.061^{\mathrm{c}}$ & 0.09 & $0.052^{\mathrm{c}}$ & 0.10 \\
\hline $\begin{array}{l}\text { Optimal amount of spraying, fertilizing, and } \\
\text { water applied; best harvest date }\end{array}$ & $0.024^{\mathrm{a}}$ & 0.14 & $0.032^{\mathrm{a}}$ & 0.17 & $0.029^{\mathrm{a}}$ & 0.16 \\
\hline Maximize crop revenue from marketing & $0.032^{\mathrm{b}}$ & 0.07 & $0.034^{\mathrm{b}}$ & 0.08 & $0.025^{\mathrm{b}}$ & 0.08 \\
\hline Lowest possible costs & 0.000 & 0.11 & 0.004 & 0.11 & 0.017 & 0.14 \\
\hline Reducing financial risk & 0.009 & 0.12 & 0.004 & 0.13 & 0.002 & 0.13 \\
\hline $\begin{array}{l}\text { Sharing limited sources of irrigation water with } \\
\text { others }\end{array}$ & $0.049^{c}$ & 0.08 & $0.056^{\mathrm{c}}$ & 0.09 & $0.050^{\mathrm{c}}$ & 0.07 \\
\hline $\begin{array}{l}\text { Reducing fertilizer and pesticides in runoff and } \\
\text { groundwater }\end{array}$ & -0.012 & 0.06 & -0.009 & 0.07 & -0.009 & 0.07 \\
\hline Sustaining rural communities & 0.004 & 0.06 & -0.003 & 0.06 & 0.006 & 0.07 \\
\hline Sum of all significant components & 0.202 & 0.54 & 0.236 & 0.61 & 0.208 & 0.64 \\
\hline
\end{tabular}

Ajzen and Fishbein (1980). As noted in Hu et al. (2006, see especially their appendix), the belief component in the first variable, $b_{j}$, was evaluated on a scale from " $0=$ extremely unlikely" to " $6=$ extremely likely" with the additional option of responding "Does not apply" to the question, "In your experience, how likely is it that these weather forecasts and information are any good at producing the following outcomes?" The list of categories in which beliefs and values were elicited is shown in Table 1 (as well as in the appendix of Hu et al. 2006). The value component for the attitude variable, $e_{j}$, was measured on the scale from " $0=$ outcome has a low value to me" to " $6=$ outcome has a high value to me" and the option of "Does not apply" for the question, "How much do you value each of these outcomes?"

The same general approach was used to measure the social (subjective) norm variable, the second independent variable on the rhs in Eq. (3), by first constructing the variable $n_{k}$ from answers to the question, "How likely is it that each of these groups believes that weather forecasts and information should influence your crop-related decisions?" A total of 14 groups are listed (Table 2): spouse/significant other, children and grandchildren, other relatives, friends and neighbors, landlord, banker or lending agency, chemical and fertilizer dealers, government agencies, data transmission network (DTN), crop consultants/local agronomists, university cooperative extension, Web sites, television and radio, and magazines and newspapers. Again, a scale was used to gauge the belief from " $0=$ extremely unlikely" to " $6=$ extremely likely" with the option of "Does not apply." The measure of motivation to comply with the other's view, $m_{k}$ in Eq. (3), was elicited from answers to the question, "How much do you value the views of these others on this matter?" between options of " $0=$ low value" to " $6=$ very high value" and "Does not apply." See Hu et al. (2006) for the description of how the scales for both of the first two variables on the rhs of Eq. (3) were converted into a 0-7 scale for statistical analyses.

As noted earlier, perceived behavioral control, the third variable on the rhs of Eq. (3), includes both the perceived controllability and self-efficacy. Self-efficacy is measured by farmers' estimates of how the influence of climate forecasts and weather information on their farming decision is limited by 1) "my ability to apply the forecasts and information" and 2) "my understanding of weather forecasts and weather information." Perceived controllability is measured by farmers' estimates of forecast limitations, such as the accuracy of forecasts, reliability of the sources making the forecasts, availability of forecasts for farming area, and the timeliness of the forecast information. Respondents scoring high on the $0-6$ scale for these factors are likely to be those who are working hard to build self-efficacy, to understand the forecast better, and to enhance personal abilities in applying the forecast. Also, they are likely more aware of the accuracy, reliability, availability, and timeliness of the forecast and most likely are influenced by the 
TABLE 2. Bagozzi test results showing components of the overall norm suggesting forecasts and weather information should influence crop-related decisions. The overall norm serving as the global view variable was measured using the question, "Lots of people may advise you that weather forecasts and weather information should influence your crop-related decisions. Generally, following this advice from others is," with responses measured on two scales: "extremely useless" to "extremely useful" and "extremely bad" to "extremely good." The responses were added to specify the global view variable (superscript "a" denotes $p<0.10$, superscript "b" denotes $p<0.05$, and superscript "c" denotes $p<$ $0.01)$. Here, $a_{3}$ is defined in Eq. (4) and $R^{2}$ denotes variance.

\begin{tabular}{lcc}
\hline \hline \multicolumn{1}{c}{ Belief and evaluation component } & $a_{3}$ & $R^{2}$ \\
\hline Spouse/significant other & -0.028 & 0.20 \\
Children/grandchildren & -0.004 & 0.11 \\
Other relatives & 0.021 & 0.11 \\
Friends and neighbors & $0.048^{\mathrm{c}}$ & 0.12 \\
Landlord & 0.007 & 0.15 \\
Banker, lending agency & $0.034^{\mathrm{c}}$ & 0.09 \\
Chemical and fertilizer dealers & $0.025^{\mathrm{a}}$ & 0.12 \\
Government agencies & $0.037^{\mathrm{b}}$ & 0.13 \\
DTN & 0.018 & 0.10 \\
Crop consultant/local agronomists & 0.006 & 0.13 \\
University cooperative extension & $0.029^{\mathrm{b}}$ & 0.13 \\
Web sites and Web sources & 0.003 & 0.08 \\
Television and radio & $0.025^{\mathrm{a}}$ & 0.12 \\
Magazines, newspapers, and newsletters & $0.019^{\mathrm{a}}$ & 0.16 \\
Sum of all significant components & 0.217 & 0.87 \\
\hline
\end{tabular}

forecast and weather information. In effect, we are indirectly measuring the extent to which the farmers are putting effort into building their skills and are paying attention to such things as accuracy and reliability and, thus, expect a positive effect on both the probability and the intensity of use.

In addition, farmers were asked "How important is it to you, personally, to have complete control over all your farming decisions?" (in contrast, e.g., to decisions being controlled by landlords, bankers and others, or by the natural system itself). Answers to this question, on the scale from " $0=$ extremely unimportant to me" to " 6 = extremely important to me," would reflect a personal desire for control in the operation [drawing on the theoretical model of Lynne and Casey (1998) and Lynne (1999)]. Thus, individuals scoring high on this question would also be more likely to be influenced by forecasts and, for those who are influenced, would likely be influenced to a greater degree. So, the PBC variable was developed by multiplying the controllability, self-efficacy, and importance variables to represent the same kind of expectancy-value, utility form used for the first two variables on the rhs of Eq. (3).

A measure of financial constraint, the $R$ term in Eq. (3), is obtained from answers to the survey request, "Please indicate the category that best describes the level of your gross farm sales in a typical year." The category of farm sales ranges from "under $\$ 10,000$ " to " $\$ 1,000,000$ or more," with several intermediate sales values. The midpoint of each sale category (e.g., $\$ 75,000$ for sale category of $\$ 50,000-\$ 99,999$ ) was used as the quantitative estimate of the farmer's financial ability and, indirectly, the motivation to obtain more profits.

Farm latitude and longitude coordinates were used to represent $L$ in Eq. (3). Farmers were asked to "Please place an $\mathrm{X}$ in the general area of the county in which most of the land you farmed in 2002 is located." Coordinates were then determined using the "3D TOPOQUADS V2.0" DeLorme proprietary geospatial software. The coordinates were then transformed into Albert's indices that indicate the farmers' location at the intersection of latitude (the "NORTHING" variable) and longitude (the "EASTING" variable).

A number of other demographic and physical descriptors of the farms also were elicited in the survey, including age, education, years in farming business, types of ownership, and marital status, as well as farmrelated attributes such as crop type, rotations, operated acres, and income-related items. These are not included in models, however, because of their likely mediation "through the various attitude, norm, and control variables" as well as the financial and location variables (Lynne et al. 1995, p. 590).

\section{d. Independent-variable component selection}

For the first two independent variables on the rhs in Eq. (3), recall that there are several components to each one, as depicted in Tables 1 and 2 [and, for the case of the first variable in Table 1, also see the appendix in $\mathrm{Hu}$ et al. (2006)]. The Bagozzi (1984) test rather than PC analysis was used in selecting the salient components from these lists of components. The reason is that PC analysis groups components based on only the internal correlation among component parts and does not consider their external relation to the overall global view toward forecasts and weather information or toward being willing to be influenced by others or general community pressure as represented in social norms. This may be misleading because loadings of some real data variables can be meaningless. For example, in the PC results, crop planting, crop insurance, financial, and crop marketing decision components were expected to be grouped into agronomic and economic subsets but were not. As we will see, in contrast, the Bagozzi test results are more logical. Another important property of the Bagozzi test is that it is insensitive to the scales used in the survey questions and so its results have general or "global" applications beyond a specific survey (Lynne et al. 1995). 
The Bagozzi test involves examining a linear relationship including the belief and value components as well as an anchor variable (interaction of belief and value for that dimension) in explaining the variation in the global view. The component is deemed a part of the global attitude or global norm if the coefficient $a_{3}$ in the following expression is significant:

Global attitude/norm $=a_{0}+a_{1}($ belief $)+a_{2}($ value $)$

$$
+a_{3}(\text { belief } \times \text { value })+\varepsilon,
$$

where $\varepsilon$ is the residual. The dependent variable in each case is developed from the question shown in the legend of Tables 1 and 2.

The application of the Bagozzi test to the attitude data is demonstrated in Table 1. The overall experience with forecasts and weather information is composed of the agronomic decisions represented in the first (planting the best crop) and third items (optimal time to fertilize), the right amount of crop insurance, maximizing crop revenue, and sharing irrigation water during droughts, for all three types of forecasts. A sum of these components was used to form the first independent variable on the rhs in Eq. (3), which explains 54\%-64\% of the variation in the global attitude described in the legend to Table 1.

Results from applying the Bagozzi test to select the components of the social norms are given in Table 2 and suggest that friends and neighbors, banker or lending agency, chemical and fertilizer dealers, government agencies, university cooperative extension, television and radio, and magazines/newspapers/newsletters are the major factors, in descending importance, composing the norm variable. A sum of these salient components is used to form the second independent variable on the rhs in Eq. (3); this sum explains $87 \%$ of the variation in the global norm described in the legend to Table 2.

\section{e. Statistical model and tests for heteroskedasticity}

Specifics of the data and use of the censored dependent variable required a careful consideration in selection of the statistical procedure. Ordinary least squares (OLS), ordinal "probit", single-limit "tobit" ("Tobin's probit"), and doubly censored tobit procedures were considered.

A review of the literature on the ordinal probit and doubly censored tobit procedures indicated that these two procedures usually result in similar attributes being significant and having the same sign (Boyle et al. 2001, pp. 441, 447; MacKenzie 1993) despite the fact that ordinal probit is best suited for the analysis of an ordered categorical model that assumes responses are cardinal (Roe et al. 1996; Stevens et al. 1997) and dou- bly censored tobit for censored regression analysis that assumes responses are continuous but censored (Greene 2002). In this study, the dependent variable is doubly censored, and the focus is on both the significance of the attributes and the intensity of the influence, which ordinal probit does not provide. As a result, doubly censored tobit is preferred. In addition, the doubly censored tobit procedure [censored at both lower and upper bounds of the scale as described in Greene (2002)] was selected to correct for censoring, to retain cardinal information between the upper and lower bounds of the scale or, in other words, to eliminate the possibility of predicted values of the dependent variable being either below the lower limit or above the upper limit or upper scale of forecast influence specified in the survey questionnaire.

Comparisons of OLS versus tobit procedures show that tobit is particularly suited for a censored form of the dependent variable like $(0, X)$ with 0 meaning the farmer was not influenced and $X$ representing the extent to which an individual was influenced for that $s u b$ set who were so influenced. That is, this procedure facilitates not only relating the same causal factors to the probability of 0 or $X$ but also relates these causal factors to the degree of influence for those being influenced. According to McDonald and Moffitt (1980), the tobit method generally produces more robust and consistent results on such censored data than does the OLS model [for details of the tobit model, see Maddala (1983) and Greene (2002)].

Tobit differs from OLS in that its coefficients cannot be used directly to determine the change in behavior for a unit change in any of the independent variables. There are two ways to determine those changes. One is to apply the decomposition method of McDonald and Moffitt (1980), which gives a measure of the marginal response to a unit change in the independent variable. For a demonstration of this approach readers are referred to Norris and Batie (1987). The other way, which provides a more easily understood measure of response, is to focus on the elasticity represented in the response of the dependent variable as in 1) the percentage change in the probability that the weather and climate forecast information influences decisions at all and 2), for those who are being influenced, the percentage change in the degree of influence, in both cases the change being associated with a $1 \%$ change in the independent variable in question, that is, terms on the rhs of Eq. (3). These elasticity estimates are provided here.

Because the data were from three counties of somewhat different farming conditions, data from the survey results were examined and adjusted for heteroskedasticity using the statistical package "LIMDEP." 
TABLE 3. Agronomic behavioral influence as it pertains to current and recent-past weather information and short-term forecasts. [Superscript "a" denotes $p<0.10$, superscript "b" denotes $p<0.05$, and superscript "c" denotes $p<0.01$. The normalized coefficient (coef) is calculated by dividing the regression by the standard error of the estimate. The numbers in parentheses are the standard errors of the normalized coefficient.]

\begin{tabular}{|c|c|c|c|}
\hline Variable & Normalized coef & $\begin{array}{l}\text { Elasticity for those that } \\
\text { are not influenced }\end{array}$ & $\begin{array}{l}\text { Elasticity for those that } \\
\text { are influenced }\end{array}$ \\
\hline ATTITUDE & $\begin{array}{r}0.4000^{\mathrm{c}} \\
(0.0294)\end{array}$ & 0.6602 & 0.6640 \\
\hline NORMS & $\begin{array}{r}0.1207^{c} \\
(0.0344)\end{array}$ & 0.1279 & 0.1286 \\
\hline $\mathrm{PBC}$ & $\begin{array}{r}0.0787^{\mathrm{b}} \\
(0.0337)\end{array}$ & 0.0529 & 0.0532 \\
\hline FARMSALES & $\begin{array}{r}0.0692^{\mathrm{a}} \\
(0.0370)\end{array}$ & 0.0691 & 0.0694 \\
\hline EASTING & $\begin{array}{r}-1.0885 \times 10^{-6} \\
\left(0.9023 \times 10^{-6}\right)\end{array}$ & 0.0368 & 0.0370 \\
\hline NORTHING & $\begin{array}{c}1.3955 \times 10^{-6} \\
\left(2.2173 \times 10^{-6}\right)\end{array}$ & 1.2331 & 1.2401 \\
\hline CONSTANT & $\begin{array}{l}-2.6476 \\
(4.3519)\end{array}$ & & \\
\hline
\end{tabular}

\section{Results and discussion}

The ranges, means, standard deviations and correlations for the various variables in (3) are presented and discussed in the companion paper by $\mathrm{Hu}$ et al. (2006). The regression analysis herein focusing on causes of behavioral influence is presented in Tables 3-6 for the statistical (doubly censored tobit) version of Eq. (3):

Behavioral influence $(0, X)=\beta_{1}$ ATTITUDES $+\beta_{2}$ NORMS $+\beta_{3}$ PBC $+\beta_{4}$ FARMSALES $+\beta_{5}$ LOCATION

$$
+\beta_{0}+\varepsilon
$$

where $\beta_{0}$ is a constant and $\varepsilon$ is the residual. In Eq. (5), "LOCATION" is represented by the EASTING and NORTHING variables described earlier. Results in Tables 3-6 indicate that attitudes ("ATTITUDES" variable), social norms ("NORMS" variable), perceived behavioral control ("PBC" variable), and the financial status ("FARMSALES" variable) all have significant (in the statistical sense) influence on use of weather information and forecasts in farmers' decision behavior. The influence does not vary significantly, however, with location (EASTING and NORTHING) of their farms. Among the significant parameters, ATTITUDE shows the highest statistical significance, consistently at $p<0.01$, NORMS and PBC are significant at, respectively, $p<0.01$ and $p<0.05$ for agronomic decisions but are not significant for insurance and marketing decisions. FARMSALES is significant at $p<0.10$ in the agronomic decision under the influence of current and recent-past weather information and short-term forecasts and at $p<0.01$ in the insurance and marketing decisions. It is not significant for the agronomic decisions made under the influence of long-term forecasts. Assuring statistical significance is the essential first step before focusing on the substan- tive significance/effect and answering the question, "How much does each variable actually affect the influence, and thus the use, of climate information and forecasts?"

The answer to this question is demonstrated in the elasticity estimates shown in Tables 3-6. To be specific, a $1 \%$ change in a farmer's attitude favoring the weather and climate information and forecasts in agronomic (from planting, to growing-season, to harvest and postharvest decisions), insurance, and marketing decisions will result in $0.66 \%, 0.69 \%, 1.10 \%$, and $0.66 \%$ increases, respectively, in the probability that climate information and forecasts will influence those decisions. When further separating the farmers into two groups, one with farmers whose decisions are being influenced by forecasts and the other not being influenced, we found that farmers in the former group responded with $0.66 \%, 0.69 \%, 1.10 \%$, and $0.66 \%$ increases, respectively, in the extent to which they are influenced by a $1 \%$ change in their attitude. It also becomes clear that it may be the easiest to increase the influence of forecasts on farming decisions by further enhancing farmer attitudes favoring such information. For example, the increase of using short-term forecasts in agronomic de- 
TABLE 4. Agronomic behavioral influence as related to long-term forecasts (superscript "a" denotes $p<0.05$, and superscript "b" denotes $p<0.01$; no other variables significant at $p<0.10$ ).

\begin{tabular}{|c|c|c|c|}
\hline Variable & Normalized coef & Elasticity for those that are not influenced & Elasticity for those that are influenced \\
\hline ATTITUDE & $\begin{array}{c}0.3820^{\mathrm{b}} \\
(0.0288)\end{array}$ & 0.6920 & 0.6917 \\
\hline NORMS & $\begin{array}{r}0.0818^{\mathrm{a}} \\
(0.0365)\end{array}$ & 0.1021 & 0.1020 \\
\hline PBC & $\begin{array}{r}0.1106^{\mathrm{b}} \\
(0.0338)\end{array}$ & 0.0853 & 0.0852 \\
\hline FARMSALES & $\begin{array}{c}0.0312 \\
(0.0358)\end{array}$ & 0.0372 & 0.0372 \\
\hline EASTING & $\begin{array}{c}0.3190 \times 10^{-6} \\
\left(0.9018 \times 10^{-6}\right)\end{array}$ & -0.0127 & -0.0128 \\
\hline NORTHING & $\begin{array}{r}-1.5053 \times 10^{-6} \\
\left(2.1580 \times 10^{-6}\right)\end{array}$ & -1.5801 & -1.5795 \\
\hline CONSTANT & $\begin{array}{c}3.0953 \\
(4.2407)\end{array}$ & & \\
\hline
\end{tabular}

cisions resulting from a $1 \%$ change in $\mathrm{PBC}$ is only $0.05 \%$, less than $1 / 10$ of the $0.66 \%$ change resulting from a $1 \%$ change in attitude. Thus, it will be easier to increase the influence by changing attitudes than by changing PBC. A similarly weak effect also was found for the social norms. This comparison does not mean, however, that one should not pay attention to the variables other than attitude, because of the fact these do not play as large a role. Those variables affect development of an attitude, although such highly nonlinear effects cannot be explicitly resolved in the linear model represented in Eq. (3).

It is interesting to note that the social norms are statistically significant in influencing use of both the shortterm and long-term forecasts in agronomic decisions. A $1 \%$ increase in social norms will lead to an increase in the probability of use of the forecasts by both the "new users" and by those already using forecasts by $0.13 \%$ for the short-term forecasts/current information and
$0.10 \%$ for the long-term forecasts. These results suggest that farmers approach weather and climate forecasts by consulting with friends, neighbors, and others regarding such things as the crop type and planting date and density "to go with the flow," that is, to do what others do. On the other hand, the effect of perceived social norms disappears in the marketing and insurance decisions, indicating that the influence of climate information and forecasts is at best already internalized, and it appears that farmers are consulting others less about the use of forecasts and weather information for these decisions. The influence of others is minimal in these more profitoriented decisions.

Farmers see control as a limiting factor in agronomic decision making. According to Ajzen (2002), controllability combined with self-efficacy can explain behavior well. Adding the general preference for control further enhances the controllability and self-efficacy aspect; those wanting more control will be more likely influ-

TABLE 5. Crop insurance behavioral influence as related to weather information and forecasts with various lead times (superscript "a" denotes $p<0.01$; no other variables significant at $p<0.10$ ).

\begin{tabular}{|c|c|c|c|}
\hline Variable & Normalized coef & Elasticity for those that are not influenced & Elasticity for those that are influenced \\
\hline ATTITUDE & $\begin{array}{r}0.5261^{\mathrm{a}} \\
(0.0299)\end{array}$ & 1.0987 & 1.1014 \\
\hline NORMS & $\begin{array}{c}0.0234 \\
(0.0426)\end{array}$ & 0.0412 & 0.0412 \\
\hline PBC & $\begin{array}{c}0.0055 \\
(0.0402)\end{array}$ & 0.0060 & 0.0060 \\
\hline FARMSALES & $\begin{array}{r}0.1161^{\mathrm{a}} \\
(0.0434)\end{array}$ & 0.1903 & 0.1908 \\
\hline EASTING & $\begin{array}{r}-0.4081 \times 10^{-6} \\
\left(0.9724 \times 10^{-6}\right)\end{array}$ & 0.0229 & 0.0230 \\
\hline NORTHING & $\begin{array}{c}1.1637 \times 10^{-6} \\
\left(2.2341 \times 10^{-6}\right)\end{array}$ & 1.7075 & 1.7117 \\
\hline CONSTANT & $\begin{array}{l}-2.8935 \\
(4.3964)\end{array}$ & & \\
\hline
\end{tabular}


TABLE 6. Crop marketing behavioral influence as related to weather information and forecasts with various lead times (superscript "a" denotes $p<0.10$, and superscript "b" denotes $p<0.01$ ).

\begin{tabular}{lccc}
\hline \hline \multicolumn{1}{c}{ Variable } & Normalized coef & Elasticity for those that are not influenced & Elasticity for those that are influenced \\
\hline ATTITUDE & $0.3115^{\mathrm{b}}$ & 0.6617 & 0.6565 \\
& $(0.0213)$ & & 0.0539 \\
NORMS & 0.0345 & 0.0544 & 0.0559 \\
& $(0.0253)$ & 0.0564 & 0.1741 \\
PBC & 0.0576 & & 0.1754 \\
& $(0.0353)$ & & 0.0393 \\
FARMSALES & $0.1193^{\mathrm{b}}$ & 0.0397 & -4.0226 \\
EASTING & $(0.0326)$ & & -4.0543 \\
& $-0.7888 \times 10^{-6}$ & & \\
NORTHING & $\left(0.7357 \times 10^{-6}\right)$ & & \\
& $\left(1.0770 \times 10^{-6}\right.$ & & \\
CONSTANT & $\left(3.0005^{\mathrm{a}}\right.$ & & \\
& &
\end{tabular}

enced and, for those being influenced, will be influenced to a larger extent. Analysis of the elasticity of $\mathrm{PBC}$ on the forecasts' use and influence reveals that farmers, however, are considerably less sensitive to PBC than to changes in attitude and social norms-the elasticity ranges from $0.006 \%$ to $0.09 \%$ for a $1 \%$ change in PBC. The largest response of $0.09 \%$ is associated with the influence of long-term forecasts in the agronomic decision (Table 4). The smallest, $0.006 \%$, is for the insurance decision, indicating that farmers essentially will not respond to a change in the control variable in making such a decision (Table 5). The very act of buying crop insurance is to protect oneself from uncertain weather and climate when unsure of one's own abilities and environment, which likely explains the reason; that is, control is no longer an issue because one has bought protection against uncertain (uncontrollable) climate events.

For marketing decisions, the response to $\mathrm{PBC}$ is also weak, at only $0.06 \%$ (Table 6). Again, as in insurance decisions, the dimension of control given by forecasts is not a factor. This suggests that in marketing decisions farmers perceive control for weather and climate information and forecasts as less important than for on-farm decisions like what crop to plant or when to irrigate. This seems reasonable because farmers worry less about the crop damage once it is harvested and stored in elevators, which ensure the crop is safe from an uncertain physical environment and do not require practicing skills or abilities unknown to experienced farmers. In other words, once the crop is "in the bin" the farmer has more or less complete control over it, so controllability is not an issue any more. It is still intriguing, however, how control over the marketing decision is so weakly related to forecast use, especially with the growing perception that both the regional and interna- tional long-term forecasts and weather information will affect crop prices and should play an important part in marketing the crops.

The financial variable adds realism to the TPB model, recognizing that farmers' behavior will likely be influenced by their financial capabilities and motivations. For each $\$ 10,000$ in farm sales, the probability of the influence of forecast use on currently noninfluenced farmers will increase by $0.07 \%, 0.04 \%, 0.19 \%$, and $0.18 \%$ in the two agronomic time frames, insurance, and marketing decisions, respectively (Tables 3-6). Similar changes are observed for farmers who are already using and being influenced by forecasts. Throughout the production cycle, farmers need to make short-term decisions like fertilizing, irrigating, or harvesting crops. Heavy rains may cause fertilizer to run off or may delay harvesting, and drought can stress the crop, resulting in a lower yield. Negligence of forecasts in such short-term decisions can be costly and can affect profits. Farmers are aware of these costs, which prompt them to keep forecasts in mind. On the other hand, insignificance of the financial variable in the agronomic decisions under the influence of long-term forecasts (the low elasticity at 0.04 ; Table 4 ) may relate to the fact that farmers are very sensitive to the forecast inaccuracy and lack of reliability and timeliness in the long-run forecast. As a result, the financial aspect of the forecast is so dominated by their concern with forecast accuracy as to become latent and of insignificant influence. Said somewhat differently, not gaining more control as a result of the inaccuracy of the long-term forecast overrides any concern for the financial implications. The magnitude of the PBC coefficient in Table 4 is larger than that in Table 3, a result supporting such logic.

As in short-term agronomic and marketing decisions, negligence of forecasts will make insurance decisions 
Please rate the extent to which weather forecasts and information influenced each decision in 2002, using this scale:

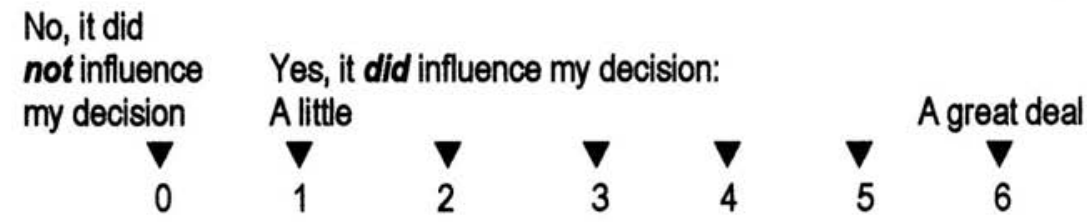

For example, if the Current and Past Conditions and Short-term Forecasts "Did not influence my decision" in "Purchasing crop insurance" at all, but the Long-term Forecasts "Did influence my decision a great deal" you might circle the numbers this way:

\begin{tabular}{|c|c|c|c|c|}
\hline $\begin{array}{l}\text { Influenced this } \\
\text { decision in 2002: }\end{array}$ & $\begin{array}{l}\text { Current and } \\
\text { Recent Past } \\
\text { Conditions }\end{array}$ & $\begin{array}{l}\text { Short-term } \\
\text { Forecasts }\end{array}$ & $\begin{array}{l}\text { Long-term } \\
\text { Forecasts }\end{array}$ & $\begin{array}{l}\text { Does } \\
\text { not } \\
\text { apply }\end{array}$ \\
\hline Purchasing crop insurance & (6) 123456 & (6) 12345 & 01123456 & 9 \\
\hline
\end{tabular}

Circle the "9" for "Does not apply" if this decision is not one you have to make.

Now, please circle a number in each of the boxes in this table, or circle the "9" for "Does not apply":

\begin{tabular}{|c|c|c|c|c|}
\hline $\begin{array}{l}\text { Influenced this } \\
\text { Decision in 2002: }\end{array}$ & $\begin{array}{l}\text { Current and } \\
\text { Recent Past } \\
\text { Conditions } \\
\end{array}$ & $\begin{array}{l}\text { Short-term } \\
\text { Forecasts }\end{array}$ & $\begin{array}{l}\text { Long-term } \\
\text { Forecasts }\end{array}$ & $\begin{array}{l}\text { Does } \\
\text { not } \\
\text { apply }\end{array}$ \\
\hline $\begin{array}{l}\text { Agronomic decisions through } \\
\text { planting (e.g., crop type, seed } \\
\text { variety, tillage, planting density } \\
\text { and date) }\end{array}$ & 0123456 & 0123456 & 0123456 & 9 \\
\hline Purchasing crop insurance & 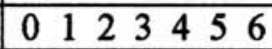 & $0 \begin{array}{lllllll}0 & 1 & 2 & 3 & 4 & 5 & 6\end{array}$ & $\begin{array}{llllllll}0 & 1 & 2 & 3 & 4 & 5 & 6\end{array}$ & 9 \\
\hline $\begin{array}{l}\text { Summer growing season } \\
\text { decisions (e.g., pesticides, } \\
\text { herbicides, fertilizer and water } \\
\text { applied) }\end{array}$ & 01223456 & 011234456 & 01223456 & 9 \\
\hline $\begin{array}{l}\text { Harvest and post-harvest } \\
\text { decisions like fall tillage }\end{array}$ & 01123456 & 011233456 & 01123456 & 9 \\
\hline Crop marketing & 01012334556 & 0102234456 & 012233456 & 9 \\
\hline Other Decisions (please specify): & 01223456 & 01223456 & 01223456 & 9 \\
\hline
\end{tabular}

FIG. A1. Survey question used to develop the dependent variable.

costly. Because of the risk of losing crops, the potential costs in failed insurance decisions are very significant. Farmers tend to focus on their financial stability in making insurance decisions, especially those who perceive less control of their financial situation (Table 5). Farmers seek profit, perhaps even maximum profits, with respect to insurance decisions. In marketing decisions, farmers are again seeking profits and may follow weather and climate forecasts in other regions that supply similar crops for that reason. Any adverse or overly favorable climatic changes in those regions will affect farmers' crop marketing decisions and profits. This orientation toward cost and profit considerations for these decisions likely explains the importance of the financial variable and, again, the little to no importance of the influence of others, in these decisions. 


\section{Concluding remarks}

This paper explores the human dimensions of the use and influence of weather and climate information and forecasts in farmer decision making. The highly significant attitude, social norm, and perceived behavioral control variables in explaining the influence of this information underline the importance of the human dimension in improving forecast use. This suggests that a focus on changing both the farmers' and their societies' beliefs and values and their perceptions of weather and climate forecasts will greatly affect their use and influence. The easiest way to improve the use and influence of weather and climate forecasts will come from changing the individual's attitude, although such change also depends on the collective "attitude" of his/her community (the social norms), for example, friends and neighbors, bankers, and university extension, toward the individual's use of climate forecasts. Working to help controllability, self-efficacy, and being responsive to the general preference for control also complements responses to changing attitudes and norms. This signals that the forecast makers should focus on changing the farmer's perception of forecast accuracy (if not the actual accuracy itself, assuming it is accurate enough; also see $\mathrm{Hu}$ et al. 2006) by making available easy-tounderstand forecasts through widely available and reliable media in a timely fashion. Thus, offering training programs to help farmers, as well as those who influence farmers, for example, crop consultants, and enhancing their understanding and ability in applying the forecasts will improve the sense of control. Anything that can be done to improve the financial viability of farms will also expand the demand for forecasts. Of interest is that finding a way for forecasts to become more influential can in itself also increase that financial capability. Because of the substantive role of control, financial and otherwise, weather information and climate forecasts will likely carry an ever more important role following the contemporary trend toward industrializing the farms, with the main goal in this trend to have more effective control of farming operations and productivity.

From a theoretical perspective, this test of the theory of planned behavior as modified by integrating it with constructs from the theory of derived demand in economics into the theory of planned demand was successful. Both the TPB construct and its extended and integrated TPD version are viable choices in understanding and predicting the influence of weather and climate forecasts. These frameworks are useful for designing ways to enhance the use and influence of climate forecasts in agricultural (and likely other kinds of) decision making. Note that this test is by no means an exhaustive one, in the sense that there remain possibilities that these models may need to be modified further. Identifying variations and the different elements affecting such variations will continuously enrich the TPB theory and its applications in decision making related to weather and climate forecasts.

Acknowledgments. The authors are grateful for the generous participation of the 724 farmers. Grant support for this study was provided by the U.S. Department of Commerce National Oceanic and Atmospheric Administration's Human Dimensions in Global Change Program (NA16GP2715) to the University of Nebraska at Lincoln and is gratefully acknowledged. We thank Professor William H. Greene of New York University for his assistance in running the LIMDEP package. We also appreciate the many helpful comments and suggestions for improvements from the reviewers and the editor for the journal. The paper is better for it.

\section{APPENDIX}

\section{Survey Question Used to Develop the Dependent Variable}

Figure A1 shows the survey question used to develop the dependent variable, as described in section $3 \mathrm{~b}$.

\section{REFERENCES}

Ajzen, I., 1985: From intentions to actions: A theory of planned behavior. Action Control, from Cognition to Behavior, J. Kuhl and J. Beckmann, Eds., Springer-Verlag, 11-39.

_ 1988: Attitudes, Personality and Behavior. The Dorsey Press, $175 \mathrm{pp}$.

_ 1991: The theory of planned behavior. Organ. Behav. Hum. Decis. Processes, 50, 179-211.

— 1996: The social psychology of decision making. Social Psychology: A Handbook of Basic Principles, E. T. Higgins and A. W. Kruglanski, Eds., Guilford Press, 297-325.

— , 2002: Perceived behavioral control, self-efficacy, locus of control, and the theory of planned behavior. J. Appl. Soc. Psychol., 32, 1-20.

ing Social Behavior. Prentice Hall, 278 pp.

Armitage, C. J., and M. C. Conner, 1999: The theory of planned behaviour: Assessment of predictive validity and "perceived control." Br. J. Soc. Psychol., 38, 35-54.

Bagozzi, R. P., 1984: Expectancy-value attitude models: An analysis of critical measurement issues. Int. J. Res. Mark., 1, 295310.

Bandura, A., 1997: Self-Efficacy: The Exercise of Control. Freeman, $604 \mathrm{pp}$.

Beedell, J., and T. Rehman, 1999: Explaining farmers' conservation behaviour: Why do farmers behave the way they do? $J$. Environ. Manage., 57, 165-176.

— , and —, 2000: Using social-psychology models to understand farmers' conservation behaviour. J. Rural Stud., 16, $117-127$. 
Boyle, K. J., T. P. Holmes, M. F. Teisl, and B. Roe, 2001: A comparison of conjoint analysis response formats. Amer. J. Agric. Econ., 83, 441-454.

Connolly, T., H. R. Arkes, and K. R. Hammond, Eds., 2000: Judgment and Decision Making: An Interdisciplinary Reader. $2 \mathrm{~d}$ ed. Cambridge University Press, 786 pp.

Cutforth, B. L., A. C. Francis, G. D. Lynne, D. A. Mortensen, and K. M. Eskeridge, 2001: Factors affecting farmers' crop diversity decisions: An integrated approach. Amer. J. Altern. Agric., 16, 168-176.

Dawes, R. M., and R. Hastie, 2001: Rational Choice in an Uncertain World: The Psychology of Judgment and Decision Making. Sage Publications, 372 pp.

Gilovich, T., D. Griffin, and D. Kahneman, Eds., 2002: Heuristics and Biases: The Psychology of Intuitive Judgment. Cambridge University Press, 857 pp.

Greene, W. H., 2002: Econometric Analysis. Prentice Hall, 1026 pp.

Hammond, K. R., T. R. Stewart, B. Brehmer, and D. O. Steinmann, 1986: Social judgment theory. Judgment and Decision Making: An Interdisciplinary Reader, H. R. Arkes and K. R. Hammond, Eds., Cambridge University Press, 56-76.

Hastie, R., 2001: Problems for judgment and decision making. Annu. Rev. Psychol., 52, 653-683.

$\mathrm{Hu}, \mathrm{Q}$., and Coauthors, 2006: Understanding farmers' forecast use from their beliefs, values, social norms, and perceived obstacles. J. Appl. Meteor. Climatol., 45, 1190-1201.

Hulme, M., and Coauthors, 1992: Seasonal rainfall forecasting for Africa. Part II: Application and impact assessment. Int. J. Environ. Stud., 40, 103-121.

Kahneman, D., 2003: Maps of bounded rationality: Psychology for behavioral economics. Amer. Econ. Rev., 93, 1449-1475.

—_ P. Slovic, and A. Tversky, Eds., 1982: Judgment under Uncertainty: Heuristics and Biases. Cambridge University Press, $555 \mathrm{pp}$.

Kim, J., and C. W. Mueller, 1978: Introduction to Factor Analysis: What It Is and How to Do It. Sage Publications, 79 pp.

Lynne, G. D., 1999: Divided self models of the socioeconomic person: The metaeconomics approach. J. Socio-Econ., 28, 267-288.

- and L. R. Rola, 1988: Improving attitude-behavior prediction models with economic variables. J. Soc. Psychol., 128, $19-28$.

- and F. C. Casey, 1998: Regulation of technology adoption when individuals pursue multiple utility. J. Socio-Econ., 27, 701-719.

- _ _ A. Aodges, and M. Rahmani, 1995: Conservation technology adoption decisions and the theory of planned behavior. J. Econ. Psychol., 16, 581-598.

MacKenzie, J., 1993: A comparison of contingent preference models. Amer. J. Agric. Econ., 75, 593-603.

Maddala, G. S., 1983: Limited-Dependent and Qualitative Variables in Econometrics. Cambridge University Press, 401 pp.

Manstead, A., and S. van Eekelen, 1998: Distinguishing between perceived behavioral control and self-efficacy in the domain of academic achievement intentions and behaviors. J. Appl. Soc. Psychol., 28, 1375-1392.

McDonald, J. F., and R. A. Moffitt, 1980: The uses of tobit analysis. Rev. Econ. Stat., 62, 318-321.

Nicholls, N., 1999: Cognitive illusions, heuristics, and climate prediction. Bull. Amer. Meteor. Soc., 80, 1385-1397.

Norris, P. E., and S. S. Batie, 1987: Virginia farmers' soil conservation decisions: An application of tobit analysis. South. J. Agric. Econ., 19, 79-90.

Plous, S., 1993: The Psychology of Judgment and Decision Making. Temple University Press, $302 \mathrm{pp}$.

Roe, B., K. J. Boyle, and M. F. Teisl, 1996: Using conjoint analysis to derive estimates of compensating variation. J. Environ. Manage., 31, 145-159.

Sonka, S., S. Changnon, S. Bard, and T. Doehring, 2001: Midwestern impacts of the 2000 drought forecasts: Final report to the University Corporation for Atmospheric Research. Ag Education \& Consulting, LLC, Savoy, IL, 97 pp.

Sparks, P., C. A. Guthrie, and R. Shepherd, 1997: The dimensional structure of the "perceived behavioral control" construct. J. Appl. Soc. Psychol., 27, 418-438.

Stevens, T. H., C. Barrett, and C. E. Willis, 1997: Conjoint analysis of groundwater protection programs. Agric. Resour. Econ. Rev., 26, 229-235.

Stewart, T. R., and C. M. Lusk, 1994: Seven components of judgmental forecasting skill: Implications for research and the improvement of forecasts. J. Forecasting, 13, 579-599.

_, W. R. Moninger, J. Grassia, R. H. Brady, and F. H. Merrem, 1989: Analysis of expert judgment in a hail forecasting experiment. Wea. Forecasting, 4, 24-34.

- R. Pielke Jr., and R. Nath, 2004: Understanding user decision making and value of improved precipitation forecasts: Lessons from a case study. Bull. Amer. Meteor. Soc., 85, 223 235.

Taylor, J. G., T. R. Stewart, and M. Downton, 1988: Perceptions of drought in the Ogallala Aquifer region. Environ. Behav., 20, 150-175.

Terry, J. T., and J. E. O'Leary, 1995: The theory of planned behaviour: The effects of perceived behavioral control and selfefficacy. Br. J. Soc. Psychol., 34, 199-220.

Trumbo, C., and G. O'Keefe, 2001: Intention to conserve water: Environmental values, planned behavior, and information effects: A comparison of three communities sharing a watershed. Soc. Nat. Resour., 14, 889-899.

Vodopivec, B., 1992: A need theory perspective on the parallelism of attitude and utility. J. Econ. Psychol., 13, 19-37.

Willock, J., and Coauthors, 1999: The role of attitudes and objectives in farmer decision making: Business and environmentally-oriented behaviour in Scotland. J. Agric. Econ., 50, 286303.

Wright, G., and P. Ayton, Eds., 1987: Judgmental Forecasting. John Wiley and Sons, 293 pp. 